\title{
SLOPE STABILITY OF RECTIFY COAL WASTE EMBANKMENTS ON MINING AREAS ${ }^{1}$
}

by

\author{
Casimir Klossek ${ }^{2}$
}

\begin{abstract}
The paper is of a theoretical and experimental character, focusing on the results of field tests on the load-bearing capacity and stability of high $(>20 \mathrm{~m}$.) transportation embankments rectified with coal waste. The embankments are located in industrial areas subjected to the intense impact of underground mining. Such phenomena are also accompanied by essential changes in the water conditions of the subsoil. The results of model tests by SIR geo-radar used to non-damaging estimation of the suffusion occurring in the embankment constructed of non-waste materials are discussed.

The numerical assessment of the filtration process has been based on the MFE and MBE programs, which are extended calculation procedures enabling the overall estimation of the redistribution of all the stressstrain components in the structure, in consideration of any hypothesis of the boundary state.
\end{abstract}

Additional Key Words: load-bearing capacity, slope stability, mining damages

\section{Introduction}

Underground mining works conducted for many years in the areas of Southern Poland have substantially interfered into the natural soil and water conditions of the land. This refers, in particular, to changes in the boundaries of local drainage basins and watersheds, ground water levels as well as in distorted flow of surface waters forming big land flows and deep water reservoirs, where both surface waters and big quantities of underground waters are directed, having been pumped from the existing and still working mining seams.

The discussed region of Bytom has been subjected to underground mining for over 100 years, with the total land surface subsidence amounting to $\sim 10 \mathrm{~m}$. Underneath the zinc and lead ores mine (located only at $80-100$ meters underground) abundant hard coal deposits are still to be extracted. Their final output up to the year 2010, irrespective of the filling

${ }^{1}$ Paper presented at the $16^{\text {th }}$ National Conference of the American Society for Surface Mining and Reclamation,

Scottsdale, Arizona, August 13-19, 1999.

${ }^{2}$ Casimir Klossek, Ph.D., D.Sc.,Prof. of Civil Eng. at Technical University of Silesia Head of Transportation Department Address: ul. Akademicka 5, 44-100 Gliwice/Poland Tel/fax: (+ 48-32) 2371186. methods applied, will result in further land subsidence of $6 \mathrm{~m}$. Altogether, 17 coal seams of the total thickness $>34 \mathrm{~m}$ have already been worked to date from below this area. Specific concentration of detrimental mining impact is commensurate with densely populated and highly industrialized part of the discussed area.

The transportation infrastructure of the discussed region has been subjected to permanent, multi-stage rectification works to secure adequate levels of the gradeline slope. These engineering activities have led to the accumulation of high embankments (up to $\sim 20$ m), which form specific dams in flooded lands. The embankments not only hinder free gravitation flow of the surface waters, but also fail to comply with the parameters of hydraulic engineering structures. Dripping waters penetrate diagonally through shells of earthen structures in an uncontrolled manner, posing severe threats to their load-bearing capacity and stability. Moreover, they restrain the continuity and safety of traffic on a two-tract railway line of primary importance.

The above-described changes in the soil and water conditions concern numerous earthen structures in mining areas. Such situation compels precise analyses and specialist tests to be conducted in the face of serious failures or even disasters, which already occurred in the past.

Proceedings America Society of Mining and Reclamation, 1999 pp 462-471

DOI : $10.21000 /$ JASMR99010462 


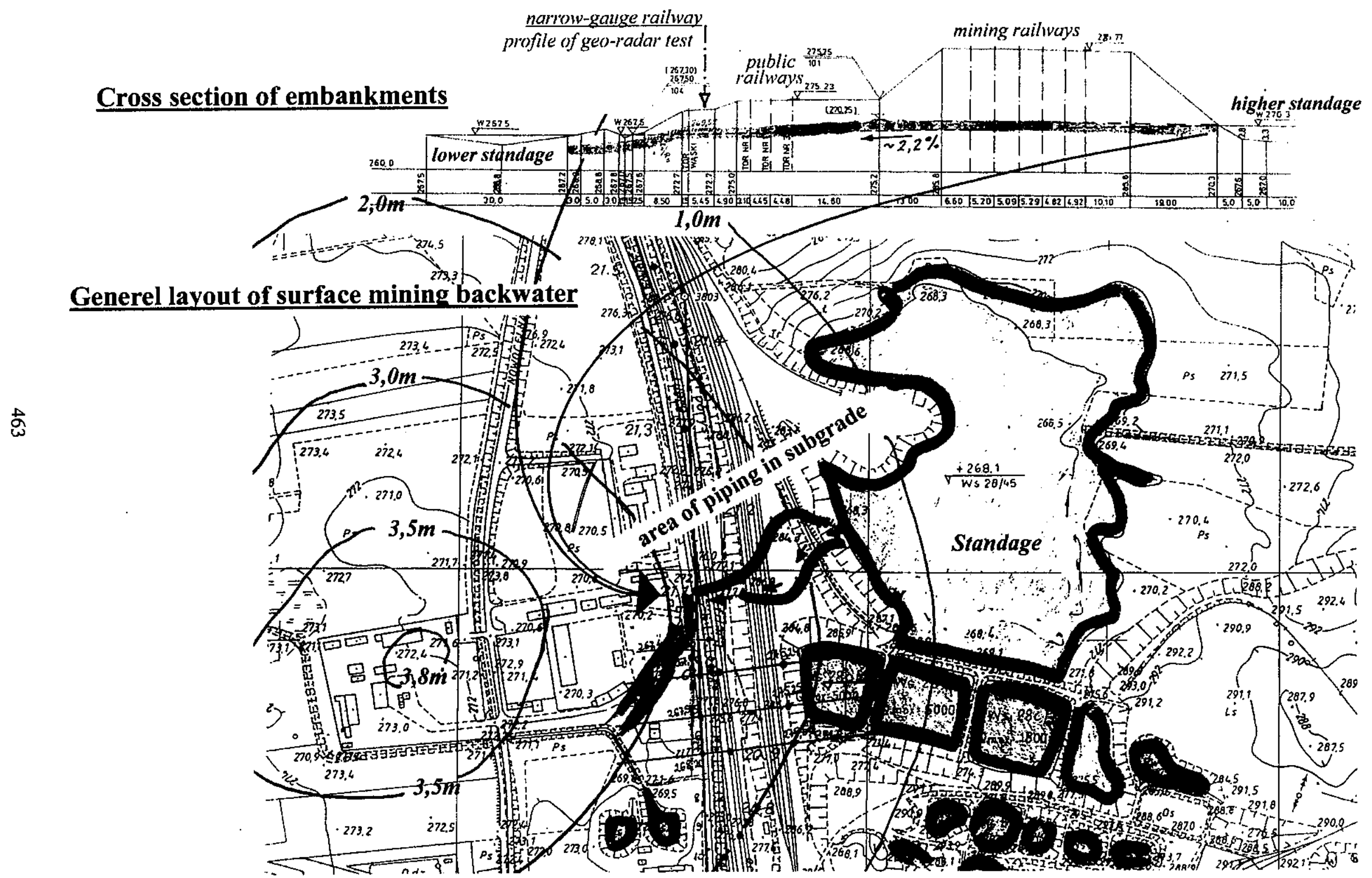

Fig.1 Location of surface land flows in the vecinity of high embankments and a forecast of further mine-induced land subsidence 


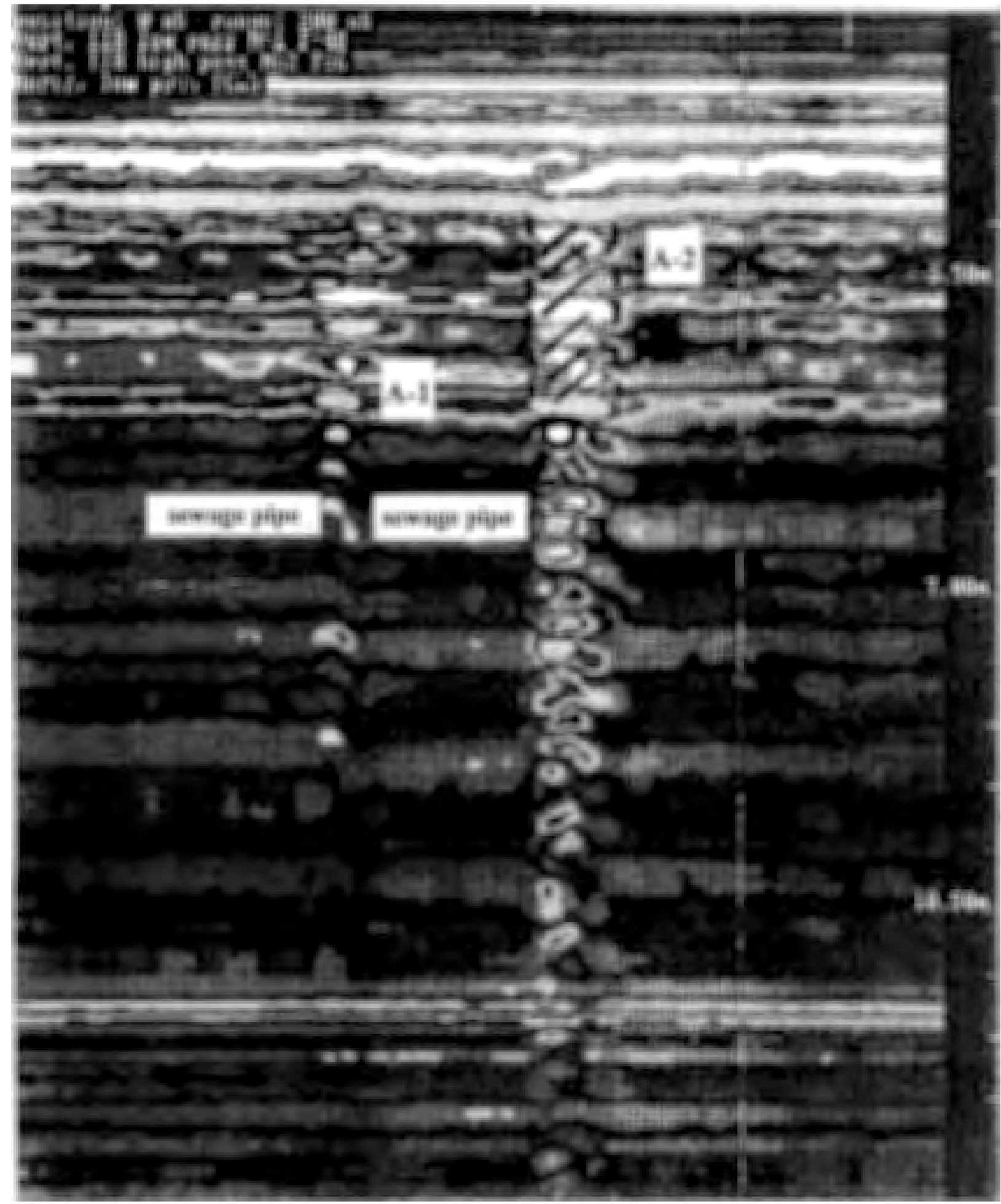

Fig. 2 Results of geo-radar tests.

Part of the wave deep cross-section in the axis of the lower embankment 


\section{Mining aspects}

The analysis of the mining extraction works completed in many successive stages to date clearly indicated extensive mining impact observed on the surface of the land. The superposition of deformation parameters, especially in respect of horizontal unitary strains, did not reveal any relaxation phenomena.

The dominating impact is constituted by the horizontal loosening strains reaching the range of 6$9 \%$. Also, in the course of mining conducted in the discussed area, permanent diagonal slope $>15-20 \% 0$ occurred, as well as considerable horizontal displacement of the rail track axes of $2.5 \mathrm{~m}$. Furthermore, the discussed area faces the threat of discontinuous deformations in the form of faults and collapse sinks.

Measurements and field observations conducted for many successive years indicated that in such conditions the total failure frequency of linear infrastructure elements rose 3-4 times.

Such rise concerns, in particular, earthen transportation structures, the safety of which is significantly reduced (Klossek 1994/95).

\section{Hydraulic engineering analysis}

Apart from mine-induced multiparametric land deformations, there are also other threats posed by variable water conditions, involving, in the discussed region, numerous surface water reservoirs adjacent to slopes of high embankments and outflows of the so called 'escape waters' ( $\sim 600 \mathrm{~V} / \mathrm{min})$, making up the difference in the levels $\Delta \mathrm{h}=3 \mathrm{~m}$.

The uncontrolled penetration of water through the embankment to the local subsidence epicenter on the opposite side, results in the loosening of the soil structure and its increased humidity. The old culvert located in this area lost its drainage a long time ago and was covered in the course of widening the embankment foundation base.

Both traditional geo-engineering drilling as well as geo-radar technology were applied to localize the discussed anomalies. The findings indicate that the embankments are mainly formed by anthropogenic grounds, consisting of mining waste shells with the addition of sand and of shells produced in the course of zinc and lead ores extraction, the parameters of which are complied in Fig.5.Tertiary deposits located in the subsoil are represented by clays, dusts $\left(I_{L}=0,4\right)$ and claystone interbedded with watered sand.

The plastic consistence of the subsoil at the foundation base of the embankment is determined by soil saturation and gravitational shapes of hydraulic slopes (2.2 - 5\%) of the mining land area as well as by tight ground water-table of high pressure $(\sim 5,9 \mathrm{~m})$. The main purpose of radar tests was not only to detect wave anomalies that facilitate the migration directions of the escape waters but also to identify the actual structure and condition of transportation embankments.

The measurements were taken by means of SIR-2 radar kit (USA made) with aerials of 120 and 200 $\mathrm{MHz}$ frequency. The applied time registration windows of $200 / 300 / 400 \mathrm{~ns}$ made it possible to penetrate waves (reflection option) up to the depth of $\sim 25 \mathrm{~m}$. The data was saved on a disc in a digital form and interpreted on the grounds of numerical procedures of transformation (filtration) and color graphic representation (amplitudes).

The measurement profiles were situated in parallel to the track axis on each of the three traffic levels (Fig.1), and perpendicularly to the area of greatest depression. An exemplary boundary profile in the zone of the escape waters outflow is presented in Fig.2. The upper part of the observed anomalies is generated by considerable loosening of the embankment subsoil at the point of the escape waters outflow. The wave representation in the lower zone is the superposition of multiple reflexes from the loosening zones and from the plugged drain of the idle culvert. Great energy of the radar reflexes registered on the wavegraph indicates that the whole subsoil is highly waterlogged. The anomalies detected in other zones give the image characteristic to voids, where big amounts of soil particles were washed away due to piping. High propagation velocity of the electromagnetic impulses occurred in the whole analyzed subsoil area, which indirectly points to the increased porosity of the subsoil.

Thus, intense traffic of heavy rail-vehicles did not bring about the reconstruction of the original material structure and its consolidation.

The results of the geo- engineering and radar tests clearly confirmed the occurrence of the detrimental changes in the hydrology and structure of the subsoil exposed to the long-term mining impact. The consequences of the changes first of all entail significant reduction of the soil primary resistance (up to $\sim 50 \%$ ), leading to temporary or permanent loss of the load bearing capacity of the subgrade (Klossek 1994).

The next stage of research involved attempts to estimate the influence of the above mentioned factors on the stability of embankments exposed to an increased mining impact. 


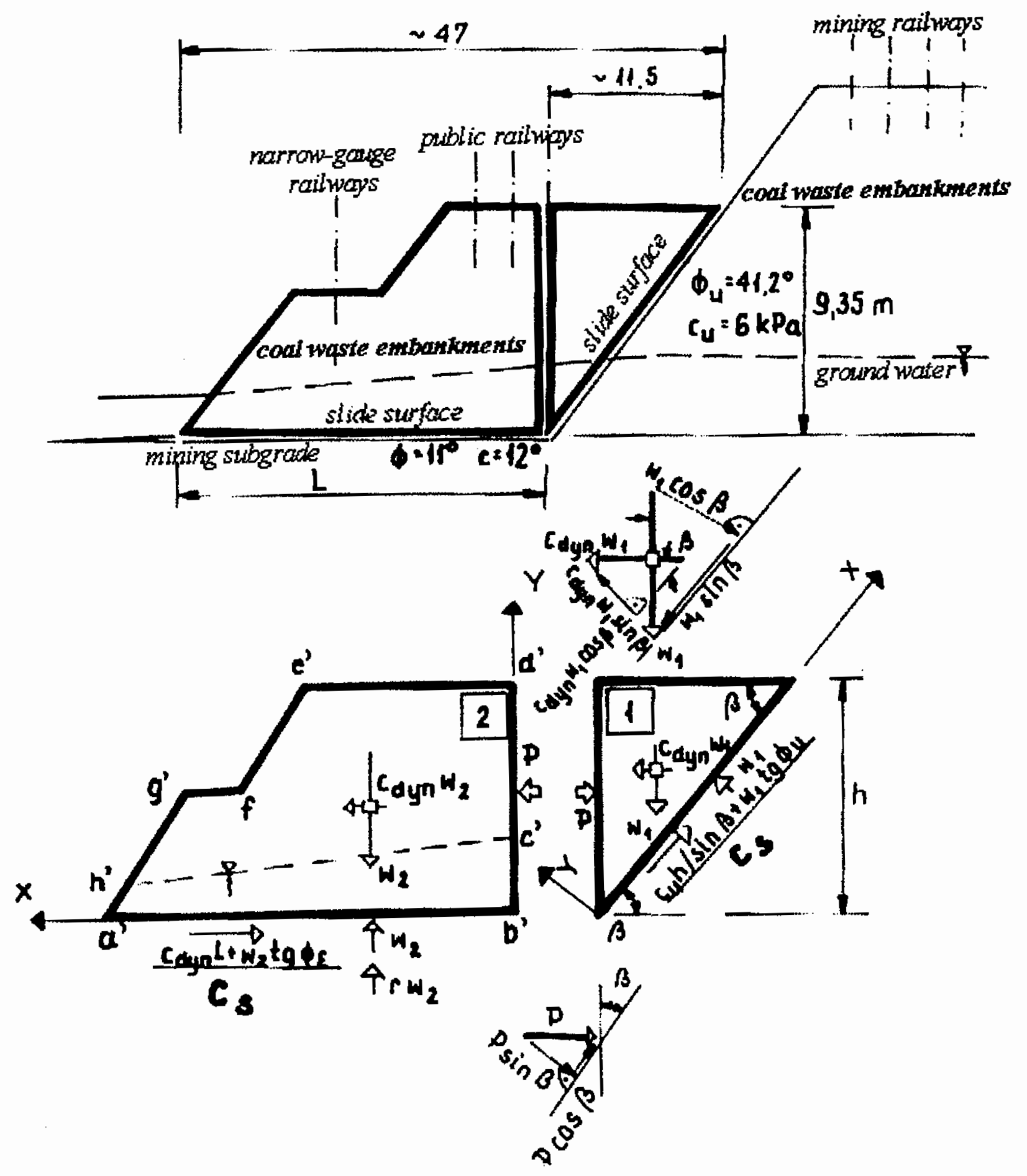

Fig.3 Calculation diagram for the block method 


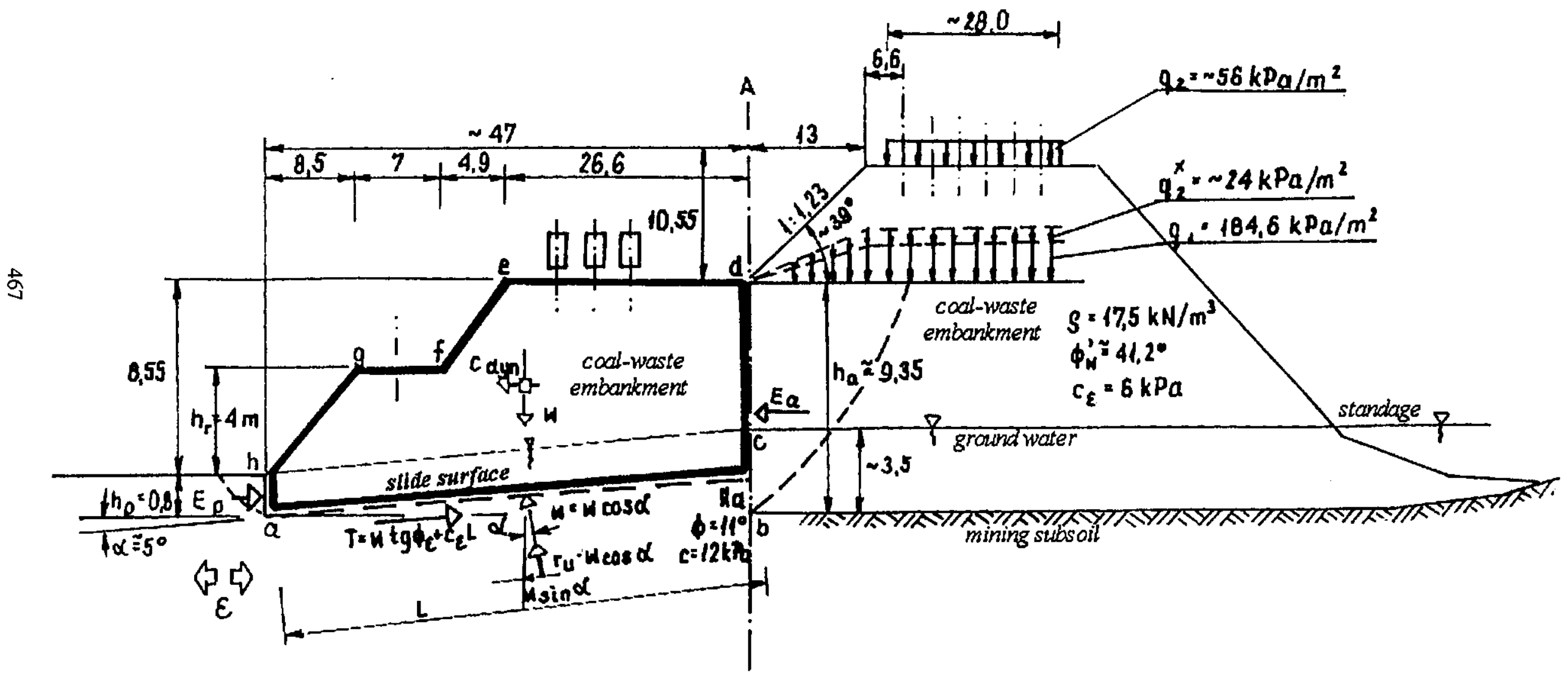

Fig. Calculation diagram for the predistined slip plane method 


\section{Estimation of the stability of embankments} exposed to the intense mining impact

The estimation of the stability of embankments was made on the grounds of three calculation methods:

- the block stiffness method,

- the predestined slip plane method,

- the finite and boundary elements method.

In the course of the calculations of the first and the second method, the following synthetic coefficients of total embankment stability $\mathrm{C}_{\text {stab }}$ were derived:

$$
\mathrm{F}_{\mathrm{m}} / \mathrm{F}_{\mathrm{u}}>\mathrm{C}_{\text {stab. }}=\mathrm{C}_{\mathrm{s}}=1.35-1.5
$$

where:

$F_{m}$-forces maintaining the eqilibrium of the structure $F_{u}$ - upsetting forces, nullifying structure stability.

The upper value of the coefficient $\left(\mathrm{C}_{\text {stab. }}{ }^{\max }>1.5\right)$ is recommended for the embankment slopes with the operation life over 25 years.

The calculations made on the basis of the third method rendered the most complete analysis of the stress-strain components, as well as the location of the plasticity zones in the subsoil in view of the assumed structural strength hypothesis.

\section{The block method}

The analysis of the stability of the multicomponent structure presented in Fig.3. was made on the assumed diagonal slip plane, corresponding to the subsoil layers. The equilibrium conditions of crosssection A-A were determined by means of the active pressure of the upper part of the embankment slope loaded with rolling stock (sliding forces) and passive earth pressure at the lower part of the slope of a narrow-gauge track, which results in the following relation:

$\mathrm{C}_{\mathrm{s}}=\left(\mathrm{W} \cos \alpha \operatorname{tg} \phi_{\varepsilon}+\mathrm{Lc}_{\varepsilon}+\mathrm{E}_{\mathrm{p}} \cos \alpha\right) /\left(\mathrm{W} \sin \alpha+\mathrm{E}_{\mathrm{a}} \cos \alpha\right)$

where:

- forces maintaining the equilibrium of the structure, determined by the dependencies: $\mathrm{T}=\mathrm{Ntg} \phi_{\varepsilon}+\mathrm{Lc} \mathrm{c}_{\mathrm{\varepsilon}}=\mathrm{W} \cos \alpha \operatorname{tg} \phi_{\mathrm{\varepsilon}}+\mathrm{Lc} \mathrm{c}_{\varepsilon}$ pressure forces and cohesion forces on the slip plane, $E_{p}=0,5 \rho h_{p}{ }^{2} \operatorname{tg}^{2}\left(\pi / 4+\phi_{\varepsilon} / 2\right)+2 c_{\varepsilon} h_{p} \operatorname{tg}\left(\pi / 4+\phi_{\varepsilon} / 2\right)$ passive earth pressure,

* sliding forces, determined by the dependencies: $E_{p}=\left(0,5 \rho h_{a}{ }^{2}+q h_{a}\right) \operatorname{tg}^{2}\left(\pi / 4-\phi_{\varepsilon} / 2\right)-2 c_{\varepsilon} h_{a} \operatorname{tg}\left(\pi / 4-\phi_{\varepsilon} / 2\right)$ $+2 c_{\varepsilon} / \rho$; active earth pressure.
After substituting suitable numerical values to the above expression, $\mathrm{C}_{\mathrm{s}}=1.23<\mathrm{C}_{\mathrm{s}}^{\max }=1.5$ was derived. For the water-logged embankment, equation (2) is modified:

$\mathrm{C}_{\mathrm{s}}=\left[\mathrm{W}\left(1-\mathrm{r}_{\mathrm{u}}\right) \cos \alpha \operatorname{tg} \phi_{\mathrm{E}}+\mathrm{L} \mathrm{c}_{\mathrm{\varepsilon}}+\left(1-\mathrm{r}_{\mathrm{u}}\right) \mathrm{E}_{\mathrm{p}} \cos \alpha\right] / \mathrm{W} \sin \alpha+\mathrm{E}_{\mathrm{a}} \cos \alpha$

where:

$r_{u}=A_{a b c h} / 2 A_{\text {abcdeftya }} ;$ porous pressure coefficient (A - water-logged area).

After successive substitutions, $\mathrm{C}_{\mathrm{s}}=1.18<1.5$ may be derived.

Considering, additionally, the dynamic influence (the rolling stock) and the paraseismic impact of mining tremors, the following equation is derived:

$$
\begin{gathered}
C_{s t a b}=\left[W\left(1-r_{u}\right) \cos \alpha \operatorname{tg} \phi_{\varepsilon}+L c_{\varepsilon}+\left(1-r_{u}\right) E_{p} \cos \alpha\right] /(W \sin \alpha+ \\
\left.E_{a} \cos \alpha+C_{d y n} W \cos \alpha\right)
\end{gathered}
$$

where:

$\mathrm{C}_{\mathrm{dyn}}$ - dynamic coefficient (lower boundary: $\sim 0.03$ ).

After suitable substitutions, $\mathrm{C}_{\text {stab }}=0.99<\mathrm{C}_{\text {stab }}{ }^{\min }=1$ is derived.

The calculation results indicate that the value of the structure safety coefficient is diminishing.

In the face of high water-logging of the subsoil and intense dynamic influence, the stability of earthen structures may reach boundary conditions, entailing the failure of their operation.

\section{The predestined slip plane method}

The calculation suppositions of the method are based on assuming potential slip planes of selected blocks, in consideration of their contact stress impact, embankment water-logging and other dynamic factors presented in the diagram in Fig.4.

In the course of the analysis of the equilibrium of the forces, the following equations may be derived for given blocks (Yang 1983):

- for block ' 1 ' from $\Sigma \mathrm{X}=0$ and $\Sigma \mathrm{Y}=0$ :

$P=\left[C_{s}\left(W_{1} \sin \beta+C_{\text {dyn }} W_{1} \cos \beta\right)-\left(c_{v} h / \sin \beta+W_{1} \cos \beta \operatorname{tg} \phi\right.\right.$

$\left.-C_{d y n} W_{1} \sin \beta \operatorname{tg} \phi\right] /\left(\sin \beta \operatorname{tg} \phi+C_{s} \cos \beta\right)$

- for block ' 2 ' from $\Sigma X=0$ and $\Sigma Y=0$ :

$\mathrm{P}=\left[\mathrm{c}_{\varepsilon} \mathrm{L}+\mathrm{W}_{2}\left(1-\mathrm{r}_{\mathrm{u}}\right) \operatorname{tg} \phi_{\mathrm{t}}\right] / \mathrm{C}_{\mathrm{s}}-\mathrm{C}_{\mathrm{dyn}} \mathrm{W}_{2}$

Comparing the two-sides of the above equations determining unknown $\mathrm{P}$, the following trinominal square is derived: 


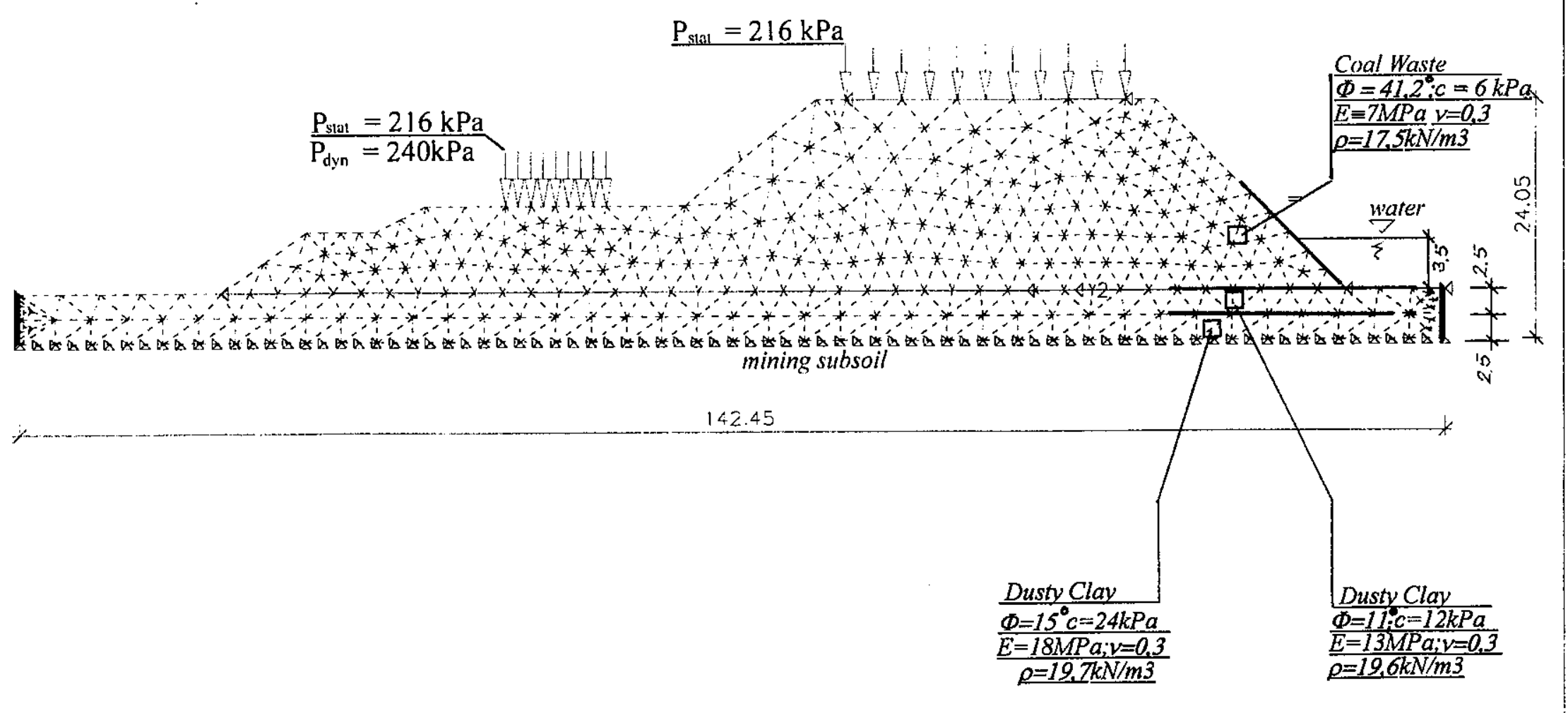

Fig.5 Calculation diagram for the discretization of the subsoil 

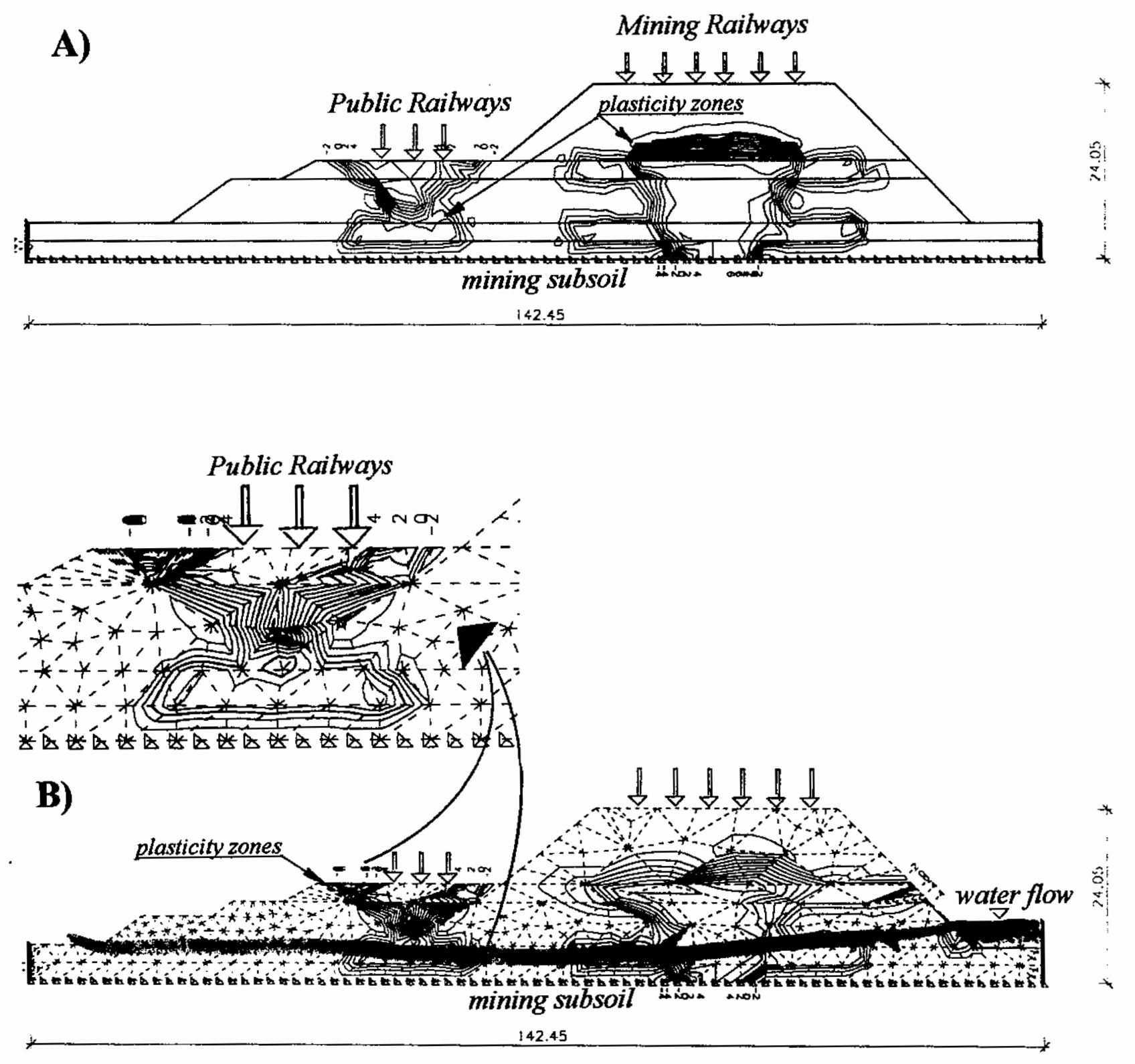

Fig.6 Location of the plasticity zones in the subsoil

A) in the absence of the water-logging conditions

$B)$ in the presence of the escape waters flow. 


$$
a C_{\text {stab }}^{2}-b C_{\text {stab }}-c=0
$$

where:

$$
\begin{aligned}
& \mathbf{a}=\mathrm{W}_{1} \sin \beta+\mathrm{C}_{\text {dyn }}\left(\mathrm{W}_{1}+\mathrm{W}_{2}\right) \cos \beta \\
& \mathbf{b}=\mathrm{c}_{\mathrm{\varepsilon}} \mathrm{h} / \sin \beta-\mathrm{C}_{\text {dyn }}\left(\mathrm{W}_{1}+\mathrm{W}_{2}\right) \sin \beta \operatorname{tg} \phi_{\varepsilon}+\mathrm{W}_{1} \cos \beta \operatorname{tg} \phi_{\varepsilon} \\
& \quad+\mathrm{L} \cos \beta c_{\varepsilon}+\mathrm{W}_{2}(1-r) \cos \beta \operatorname{tg} \phi_{\varepsilon} \\
& \mathrm{c}=\left[\mathrm{L} c_{\varepsilon}+\mathrm{W}_{2}(1-r) \operatorname{tg} \phi_{\varepsilon}\right] \sin \beta \operatorname{tg} \phi_{\varepsilon}
\end{aligned}
$$

By substituting the suitable numerical data to the above equation, $\mathrm{C}_{\text {stab }}=1.27<\mathrm{C}_{\text {stab. }}$. The obtained result signifies that although the embankment will retain its present stability, the level will be too low. Thus, it is essential to increase the horizontal forces maintaining the equilibrium of the embankment by additional engineering works, for example, buttress addition.

\section{Application of the numerical methods}

For the assumed discretization of the model as shown in Fig.5 a series of numerical tests was made. The horizontal loosening strains of the subsoil accompanying the surface deformations in mining areas were regarded as the main reason of the reduction of the subsoil compressibility module. The final effect of the calculations involved the derivation of the boundaries to the development of potential plasticity zones in the subsoil, see Fig.6 A/B.

The analysis of the results shows that at present the plasticity zones comprise considerable width and depth of the embankment foundation base. In view of the additional impact of the escape waters flow, increase in the porosity of the soil and decrease in its resistance, the range of the plasticity zones is extended, see Fig.6B.

One should not ignore the possibility of a situation, in which both plasticity zones will be combined, comprising the whole foundation base of the embankment. Such condition will be comparable to the total loss of structure stability, directly causing its failure (Klossek 1996).

\section{Conclusions}

The discussed issue involves the impact of long-term underground mining on the load-bearing capacity and stability of surface earthen engineering structures such as: road and railway embankments, drainage and water reservoir embankments, etc.

Mine-induced land deformations and dynamically changing hydro-geological conditions of the discussed area disturb the interaction between the structure and the subsoil.
This concerns, in particular, transportation engineering structures, which, due to the necessary rectification works, have already reached certain heights.

The anthropogenic media used in rectification works (such as mining waste, mainly coal shells) do not fulfill all structural requirements, because they are characterized by excessive water permeability, susceptibility to the loosening forces and increased porosity.

The plasticity zones that develop in the subsoil lead to temporary or permanent loss of its load-bearing capacity. This condition is further worsened by uncontrolled surface water flows, variations in the pressure of the water-bearing layers with tight ground-water-table, etc.

In view of this, it is essential to conduct preventive mining and engineering works, as well as constant scientific supervision of these phenomena. The discussed methods of the analyses and the obtained results may constitute a basis for effective preventive measures of the surface protection of highly degraded mining areas.

\section{Literature Cited}

Klossek K. 1994. Prevention of damage to highways and railroads in mining areas. Proceedings of the Int.Land and Mine Drainage Conf., (Pittsburgh, PA, April 24-29,1994):101-110. https://doi.org/10.21000/JASMR94040101

Klossek K. 1995. Earthen structures in mining areas. Proceedings of the $12^{\text {th }}$ National Meeting of the ASSMR (Gillette, WY, June 5-8, 1995):

https: 494-501.

Klossek K.\& Frydrych K. 1995. Technologies of mining waste utilization in engineering structures with the application of geosynthetics. Proceedings of the $11^{\text {th }}$ International Conference on Solid Waste Technology and Management. Philadelphia, PA: 311-318.

Klossek K.. 1996. Use of geosynthetics for strengthening road surface and subbase in areas with mining activity. : Proceedings of the International Symposium on Earth Reinforcement (Fukuoka,Kyushu,Japan, November 12-14 1996)Ed,A.A.Balkema, Rotterdam:609-614.

Yang $\mathrm{H}$. Huang 1983. Stability analysis of earth slopes. Van Nostrand Reinhold Comp., NY. 